\title{
Drug Therapy Problems and the Role of
Pharmacist in Surgery Ward: Prospective Observational and Interventional Study
}

This article was published in the following Dove Press journal:

Drug, Healthcare and Patient Safety

\author{
Gosaye Mekonen Tefera (D) \\ Ameha Zewudie Zeleke (iD) ${ }^{2}$ \\ Yitagesu Mamo Jima ${ }^{2}$ \\ Tsegaye Melaku Kebede (D) ${ }^{3}$ \\ 'Department of Pharmacy, Ambo \\ University, Ambo, Ethiopia; ${ }^{2}$ Department \\ of Pharmacy, Mizan-Tepi University, \\ Mizan Teferi, Ethiopia; ${ }^{3}$ School of \\ Pharmacy, Department of Clinical \\ Pharmacy, Jimma University, Jimma, \\ Ethiopia
}

Background: Drug therapy problems (DTPs) are of major concern in health care because of the associated increased cost of treatment, morbidity, and mortality. Thus, clinical practice should constitute the mainstream practice of clinical pharmacy in every ward. However, nothing is known about DTPs and the role of clinical pharmacist in the surgical ward of Ethiopia (the neglected ward). Objective: To assess the prevalence of DTP among patients hospitalized at the surgical ward and the role of clinical pharmacists in their identification and resolution.

Methods: Hospital-based prospective observational and interventional study design was used with daily patients' chart review using a semi-structured questionnaire among hospitalized adult patients at the surgical ward. After identification of DTP, verbal communication was used as a means of intervention with the treating physician. Acceptance of clinical pharmacist's intervention was considered only if a change was made to the patients' medication order. To identify determinants of DTPs, multiple stepwise forward logistic regression analysis was done by SPSS version 20.0. Statistical significance was considered at p-value $<0.05$. Written informed consent was sought and the data were secured.

Results: The response rate was $97.1 \%$ (300) for the final analysis. The mean $( \pm \mathrm{SD}=$ standard deviation) age of the participants was $42.62 \pm 18.29$ with male $(67 \%)$ predominance. DTP was identified in $76 \%$ of study participants. A total of 449 DTPs were identified, which equates with an average of 1.97 per patient. Dose too low 124/449 (27.6\%) and dose too high $81 / 449(18.0 \%)$ were found to be the most common types of DTPs. The intervention rate was $86.0 \%$ (196/228 per patients) and 86.2\% (387/449 DTPs), with the acceptance rate of $85.2 \%$ (167/196 per patients) and 78\% (302/387 per DTP) which mean (67.3\%) 302/449 of the problems were fully resolved by the clinical pharmacist. Poly-pharmacy [AOR, 7.23; 95\% CI, 2.29-22.13: P-value $<0.001$ ] and hospital stay $>20$ days [AOR, 5.42; 95\% CI, 2.74$10.70 ; \mathrm{p}<0.001]$ were the only independent predictors for DTPs.

Conclusion and Recommendation: This study identified a high prevalence of DTP which was independently predicted by the presence of poly-pharmacy and $>20$ days of hospital stay. The rate of intervention provided and acceptance from the physician was high, which is one indicator that the role of clinical pharmacists in the identification and resolution of DTP was paramount in the surgery ward and should be implemented as a must not as optional.

Keywords: drug therapy problem, surgery, clinical pharmacist, intervention, Ethiopia

\section{Introduction}

Medicine is an ever-changing science, which will make the health-care system extremely complex. In this sense, it is important to assess risk and damage to patients in the search for ultimate patient safety. ${ }^{1,2}$ Though Surgery is an essential
Correspondence: Gosaye Mekonen Tefera

Email gosi2010pharma@gmail.com 
component in health care, complications after surgery account significantly for morbidity and mortality; mainly related to anesthesia and surgical site infection. ${ }^{3}$ Besides, patients admitted to the surgery ward might receive a large number of drugs both for surgery and unrelated to surgery, hence, be at risk for drug therapy problems (DTPs) and postoperative complications. Therefore, it needs early identification and resolution. ${ }^{4}$

The concept of pharmaceutical care and DTP in its modern sense was introduced in 1980 and 1990, respectively: the pharmacist assures optimally safe and effective drug therapy by improving the organizational structures. ${ }^{5,6}$ Pharmacists have the expertise to detect, resolve, and prevent medication errors and drug therapy problems. ${ }^{7}$ These practices demonstrated a positive impact on patient safety. ${ }^{8}$

DTPs are of major concern in health care, because of the associated increased cost of treatment, morbidity, and mortality. ${ }^{9}$ In the USA, DTPs were 4th-6th cause of death with the total costs of 130 to $177.4 \$$ billion. ${ }^{10,11}$ DTP is an unwanted effect that can occur everywhere, inpatient or outpatient, in every ward where drug therapy is applied for prevention, diagnosis, or management of the disease, irrespective of age, sex, drug class, and type of disease under treatment. ${ }^{5,6}$ Indeed, these problems are most of the time preventable with multidisciplinary team incorporation during the patient care process. ${ }^{9,12-14}$

The clinical pharmacy service was started in Ethiopia in 2013 by Jimma University. ${ }^{15}$ However, in the developing countries, including Ethiopia, several barriers were encountered for fully implementing clinical pharmacy service. Some of the barriers were the non-continuity of the service due to the lack of trained personnel, the inadequacy of service promotions, Doctors and nurses had limited experience of working with pharmacists (vague idea about the role of pharmacist) which decreased the cooperation from health workers, poor drug information services, lack of commitment and lack of confidence among clinical pharmacists, and conflict of interest due to the unclear scope of practice. ${ }^{16-19}$ Besides this, in Ethiopia little or no clinical pharmacists were assigned in the Surgery ward, by the assumption of less DTP prevalence in this ward. This made it the neglected ward in-terms of clinical pharmacy service in the country. ${ }^{15}$ Thus, still today the health-care system in the developing country is known for its abundance in DTPs.

Thus, the allocation of clinical pharmacists and pharmacologists to make the multidisciplinary approach as one solution for the prevention of DTP occurrence is paramount. ${ }^{12}$ Also, clinical pharmacists are well-trained professionals in preventing and reducing the consequence of DTPs. ${ }^{20,21}$ Thus, they are found to be cost-effective. Therefore, clinical practice should constitute the mainstream practice of clinical pharmacy in every ward rather than an "optional" specialty. ${ }^{5}$ Indeed, to make the benefit a real, their intervention should be accepted and implemented. ${ }^{13,14,22,23}$

With the growing number of diseases and advances in pharmacotherapy worldwide and the ever-increasing practice of drug therapy use in surgery; understanding the nature of DTPs as well as the role of clinical pharmacists in identifying, preventing, and resolving of DTP is useful in preparing interventional strategies to reduce DTPs. However, no retrieved study in Ethiopia that assessed the DTPs and the role of clinical pharmacists in the surgery ward. Hence, the current study was done with the following objectives; (1) To assess the prevalence of drug therapy problems among patients admitted at surgical ward; (2) To determine predictors for drug therapy problems among patients admitted at surgical wards; and (3) To assess the rate of clinical pharmacists' recommendations accepted by the health-care provi$\operatorname{der}(\mathrm{s})$.

\section{Methods and Participants Study Area and Period}

This study was done parallel with other studies, ${ }^{24}$ from April 24 to July 24/2017 at Jimma University Medical Center (JUMC). Currently, it is providing services for approximately 15,000 inpatient, 160,000 outpatient attendants, 11,000 emergency cases, and 4500 deliveries per year; the catchment population of about 15 million people. The surgery department has been run by 8 seniors, 43 residents, 5 general practitioners, and medical interns as rotation and provides services approximately for 5060 patients annually.

\section{Study Design}

A hospital-based prospective observational and interventional study was used.

\section{Population}

Source population: All patients who were admitted to the surgical ward. 
Study population: Patients who were admitted to the surgical ward for surgery and who were on drug therapy or candidate for drug therapy with inclusion criteria.

\section{Inclusion and Exclusion Criteria Inclusion Criteria}

Patients admitted at the surgical ward and on drug therapy or candidate for drug therapy at the time of data collection. Age of greater than or equal to 18 years and admitted in the surgery ward at least for $24 \mathrm{hrs}$.

\section{Exclusion Criteria}

Those who were not willing to participate transferred to other ward or patients only on topical drug therapy.

\section{Sample Size and Sampling Technique}

Sample size (n) was calculated by using a single population proportion formula; except the proportion of DTP that was assumed as $50 \%$ in surgery ward, ie, $p=0.5$; all other assumptions were similar with our previous publication, where $\mathrm{Z}$ - the level of confidence at $95 \% \mathrm{CI}=1.96$, $\mathrm{W}$-margin of error $=0.05$ and $\mathrm{N}$ - the size of the population that the sample is to represent $=1265,{ }^{24}$

$n=\left(Z_{\alpha 2}{ }^{2}\right) * P(1-P) W^{2}=1.96^{2} * 0.5 * 0.50 .05^{2}=384$

Since $\mathrm{N}$ is less than 10,000 , correction formula was used as follows

$$
\begin{aligned}
n f & =n 1+n N=3841+3841265 \\
& =294+5 \%(\text { non }- \text { response })=309
\end{aligned}
$$

Surveillance by using a consecutive type of sampling technique was used to collect data from 309 patients.

\section{Study Variables \\ Dependent Variable}

Drug therapy problems (DTPs)

\section{Independent Variables}

Patient-related factors: Age, sex, socioeconomic status, education, marital status, smoking status, and patients' medication-taking behaviors. Disease-related factors: Types of surgery (elective and emergency), type of wound class, type of procedure, American Society of Anesthesiology (ASA) class, Co-morbid conditions, Charlson co-morbidity index (CCI), and length of hospital stay (LOS). Drug-related factors: poly-pharmacy, dosage regimen, pre-admission medication use, and drug-drug interaction. Health professional/facility-related factors: Timing of SAP administration, duration of treatment and prophylaxis, availability of preferred drugs for a specific condition, drug selection, the acceptance rate of clinical pharmacist intervention.

\section{Data Collection Instrument}

A semi-structured questionnaire (English version) was used with a slight modification of the previous data abstraction tool. ${ }^{24}$ This tool contains five parts, part I (socio-demographic characteristics), part II (patient's clinical information), part III (patient's medication information), part IV (drug therapy problems and pharmacists intervention acceptance), and part V (Naranjo adverse drug reaction causality assessment scale).

\section{Data Collection Process and Quality Assurance}

All patients included in the study were followed daily until discharge. Data were collected daily from each patient (ie, patients are visited by data collectors daily and by surveillance team accordingly) for the presence of any change to their treatment. Thus, it is not a single time observation. DTP classification was according to Robert J. Cipolle's textbook of pharmaceutical care practice with slight modification; there are seven types of DTPs (untreated condition, unnecessary drug, too low dose, ineffective drug, ADR, dose too high, non-compliance). The eighth was unclassified; DTP which do not fulfill the above criteria This order is significant in that it describes the rational decision-making process of the pharmacotherapy. ${ }^{25}$

The study outcome (DTP) was identified by reviewing the data that were gathered by data collectors and/or the patients' chart (in a special case for clarity) then it was evaluated in line with different most recent national and international guidelines, ${ }^{26-32}$ as well as pharmacotherapy textbooks. ${ }^{33,34}$ Furthermore, the "Medscape ${ }^{\circledR}$ online drug interaction checker", "Hippocrates ${ }^{\circledR}$ online drug interaction checker", and "Micromedex ${ }^{\circledR}$ ", were used to detect whether drug-drug interactions between the concurrently given medications exist or not, and classified under DTP if it was serious and contraindicated (per Medscape ${ }^{\circledR}$ ) by the surveillance team. Age-adjusted Charlson co-morbidity index (21 items) $)^{35}$ and Naranjo scale, ${ }^{36}$ (10 items) were used for scoring of co-morbidity and causality of adverse drug reaction, respectively. Some parts (the one that was used to collect information directly from patient or attendant, like socio-demographic, compliance, informed consent, and information sheet) of the semi-structured 
questionnaire were translated to Afan Oromo \& Amharic, and back to English by different person. The training was given for data collectors for 2 days ahead of the data collection period. Then, a pilot test for 15 patients admitted to the surgical emergency department was done and appropriate changes were made based on expert opinion. The data collectors had recorded all important information as outlined on the data abstraction tool.

Then, the investigators (one senior clinical pharmacist and three post-graduate clinical pharmacy students) and one senior surgery resident as a surveillance team had discussed the treatment given based on the collected data and new information available for the given patient daily at the end of data collection (5:00 PM). Thus, the identified DTP was recorded on the provided space by the principal investigator, based on the agreement of the team. For the identified DTP (s), on the second day of bedside round, a verbal intervention was forwarded by investigators to the treating physician to resolve it and rate of acceptance was measured by using (PCNE, Classification for Drug therapy problems V7.0); ${ }^{6}$ as an indicator of clinical pharmacist's role. Then, the patients were followed again for new DTP as well as for any modification to patients' medication orders, as a result of clinical pharmacists' intervention (acceptance status) (Figure 1).

\section{Statistical Analysis}

Before entry to EpiDATA manager/client ${ }^{\circledR}$, data was coded, checked for completeness and accuracy. Then any erroneous, ambiguous and incomplete data were excluded from final analysis. ${ }^{24}$ The data were analyzed by SPSS version 20 using descriptive statistics such as frequency and percentage for categorical variables, as well as a measure of central tendency; mean and median for continuous variables. A multivariable stepwise forward logistic-regression model was created for all independent variables to predict risk factors for DTPs. A probability value of less than 0.05 was accepted as statistically significant.

\section{Ethical Consideration}

The ethical clearance was obtained from Jimma University, Institute of Health; Institutional Review Board approved the

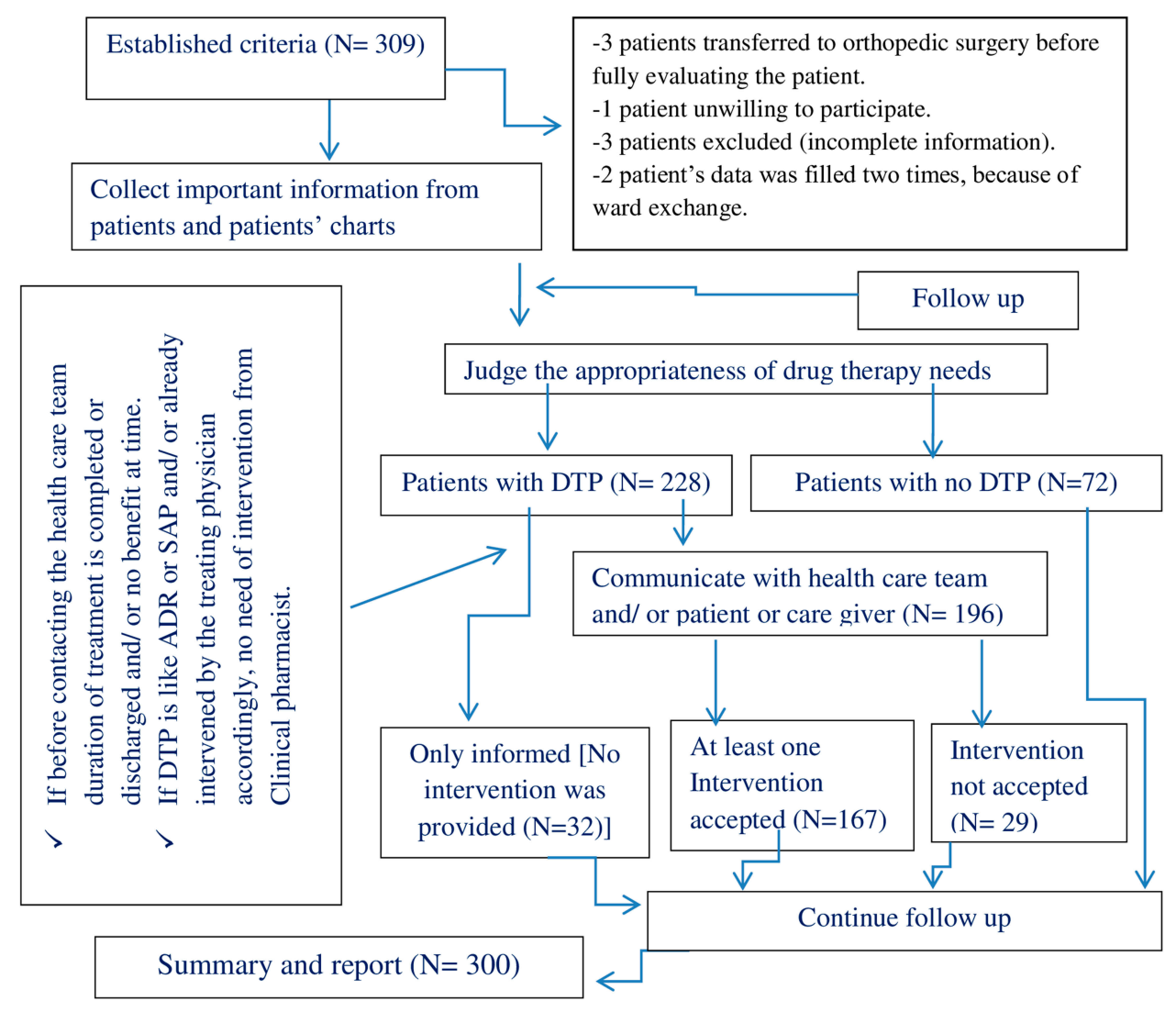

Figure I Flow chart for study participant recruitment, drug therapy problem identification, and intervention. Abbreviations: ADR, adverse drug reaction; DTP, drug therapy problem. 
study under protocol number IHRPGQ/103/207. Besides, permission was sought from the respective heads of the Department of Surgery to conduct the study in the surgery ward. After relevant information was given on the research purpose and process, written informed consent was obtained, and confidentiality was secured.

\section{Operational and Standard Definitions}

Drug therapy problem is an event or circumstance involving drug therapy that actually or potentially interferes with desired health outcomes. ${ }^{5,6}$ Acceptance for intervention: if the recommendation provided by clinical pharmacists are accepted and changed for the patients to use the newly recommended drug therapy by a health-care provider or patients. ${ }^{6,37}$

\section{Results}

\section{Characteristics of the Study Participants}

Of 309 candidate patients, 300 were included in the final study result analysis (Figure 1). The mean $\pm \mathrm{SD}$ age of the participant was $42.62 \pm 18.29$ while the majorities were male $(67 \%){ }^{24}$ The overall prevalence of co-morbid condition was (43.7\%); the majority of them were diagnosed (before and/or after admission) to have an infectious disease $(26.16 \%)$ followed by cardiovascular disorders $(19.77 \%)$ as the most common co-morbid condition. The median \pm SD length of hospital stay was $18 \pm 20.64$. The most frequently performed surgical procedures were upper and lower gastrointestinal tract (GIT) (28.7\%), skin and deep tissue (incision, drainage, skin graft, local excision, etc.) $(21.7 \%)$ and genito-urinary $(17.3 \%)$ (Table 1$)$.

Table I Characteristics of the Study Participants ( $N=300)$

\begin{tabular}{|c|c|c|c|}
\hline Variables & Categories & Frequency & Percent \\
\hline Age in years & Mean $\pm S D=42.6 \pm 18.29$ & Mini $=18$ & Maxi $=96$ \\
\hline Sex & Male & 201 & 67.0 \\
\hline $\begin{array}{l}\text { Length of hospital stay (LOS) in days } \\
\text { Co-morbid condition }(n=300)\end{array}$ & $\begin{array}{l}\text { Median } \pm S D=18 \pm 20.64 \\
\text { Yes } \\
\text { No }\end{array}$ & $\begin{array}{l}\text { Mini= I } \\
131 \\
169\end{array}$ & $\begin{array}{l}\text { Maxi= } 127 \\
43.7 \\
56.3\end{array}$ \\
\hline Common co-morbid condition $(\mathrm{N}=|3|)$ & $\begin{array}{l}\text { Infectious disease } \\
\text { Cardiovascular disorder } \\
\text { Neuro-psychiatric disorder } \\
\text { Hematologic disorder } \\
\text { GIT disorder } \\
\text { Endocrine disorder } \\
\text { Renal disorder } \\
\text { Cancer } \\
\text { Respiratory (asthma/COPD) } \\
\text { Electrolyte disorder } \\
\text { Total }\end{array}$ & $\begin{array}{l}45 \\
34 \\
16 \\
13 \\
13 \\
11 \\
11 \\
10 \\
6 \\
4 \\
172\end{array}$ & $\begin{array}{l}26.16 \\
19.77 \\
9.30 \\
7.56 \\
7.56 \\
6.40 \\
6.40 \\
5.81 \\
3.49 \\
2.33 \\
100.00\end{array}$ \\
\hline Types of surgical procedure $(\mathrm{N}=300)$ & $\begin{array}{l}\text { Upper and lower GIT } \\
\text { Skin and deep tissue (incision, drainage, local excision, skin graft) } \\
\text { Genitourinary } \\
\text { Head and neck } \\
\text { Cardiothoracic } \\
\text { Neurosurgery (craniotomy) or craniostomy } \\
\text { Amputation } \\
\text { Biliary tract } \\
\text { Breast } \\
\text { Hernia repair } \\
\text { Other*** }\end{array}$ & $\begin{array}{l}86 \\
65 \\
52 \\
41 \\
11 \\
9 \\
8 \\
7 \\
6 \\
6 \\
9\end{array}$ & $\begin{array}{l}28.7 \\
21.7 \\
17.3 \\
13.7 \\
3.7 \\
3.0 \\
2.7 \\
2.3 \\
2.0 \\
2.0 \\
3.0\end{array}$ \\
\hline
\end{tabular}

Notes: Other***, orthopedic, vascular surgery, joint (biopsy), joint and bone, joint surgery.

Abbreviations: GIT, gastrointestinal disorder; COPD, chronic obstructive pulmonary disease. 


\section{Medication Information of Study}

\section{Participants}

Regarding the pattern of drug use, only $2 / 300(0.7 \%)$ of patients did not use antimicrobial, because this study was done in the surgery ward, where antimicrobials are in use for surgical prophylaxis or treatment of infection than any other wards. Eighteen percent of patients had a history of pre-admission medication. The mean \pm SD history of medication use of the study participants' was $4.25 \pm 1.702$. Drug-drug interaction was detected in $31 \%$ of the study participants. However, the majority of those drug-drug interactions were classified as significant interaction $(97.8 \%)$ followed with minor interaction (65.6\%). Furthermore, actual ADR was detected in 5/ $300(1.67 \%)$ of study participants (Table 2$)$.

Table 2 Medication Information for the Study Participants

\begin{tabular}{|c|c|c|c|}
\hline Variables & Categories & Frequency & $\%$ \\
\hline $\begin{array}{l}\text { The pattern of drug use } \\
\text { at the surgery ward } \\
(\mathrm{N}=300)\end{array}$ & $\begin{array}{l}\text { Antibiotic only } \\
\text { Antibiotic + drug } \\
\text { for non infectious } \\
\text { Drug for non- } \\
\text { infectious only }\end{array}$ & $\begin{array}{l}19 \\
279 \\
2\end{array}$ & $\begin{array}{l}6.3 \\
93.0 \\
0.7\end{array}$ \\
\hline $\begin{array}{l}\text { History of pre-admission } \\
\text { (to the surgery ward) } \\
\text { medication use }(\mathrm{N}=300)\end{array}$ & $\begin{array}{l}\text { No } \\
\text { Yes }\end{array}$ & $\begin{array}{l}245 \\
55\end{array}$ & $\begin{array}{l}81.7 \\
18.3\end{array}$ \\
\hline $\begin{array}{l}\text { History of medication } \\
\text { use during } \\
\text { hospitalization period } \\
\text { per patient }\end{array}$ & $\begin{array}{l}\text { Mean } \pm S D \\
\text { Minimum- } \\
\text { maximum }\end{array}$ & $\begin{array}{l}4.25 \pm 1.702 \\
1-10\end{array}$ & \\
\hline $\begin{array}{l}\text { Is there drug-drug } \\
\text { interaction }(\mathrm{N}=300)\end{array}$ & $\begin{array}{l}\text { Yes } \\
\text { No }\end{array}$ & $\begin{array}{l}93 \\
207\end{array}$ & $\begin{array}{l}31.0 \\
69.0\end{array}$ \\
\hline $\begin{array}{l}\text { Significance or level of } \\
\text { drug-drug interaction } \\
\text { (Medscape }{ }^{\circledR} \text { online) } \\
(\mathrm{N}=93)\end{array}$ & $\begin{array}{l}\text { Contra-indicated } \\
\text { Serious } \\
\text { interaction } \\
\text { Significant } \\
\text { interaction } \\
\text { Minor interaction }\end{array}$ & $\begin{array}{l}1 \\
7 \\
91 \\
61\end{array}$ & $\begin{array}{l}1.1 \\
7.5 \\
97.8 \\
65.6\end{array}$ \\
\hline $\begin{array}{l}\text { Patients with actual } \\
\text { ADR in the hospital } \\
(\mathrm{N}=300)\end{array}$ & $\begin{array}{l}\text { Yes } \\
\text { No }\end{array}$ & $\begin{array}{l}5 \\
295\end{array}$ & $\begin{array}{l}1.67 \\
98.33\end{array}$ \\
\hline $\begin{array}{l}\text { Classification of ADR } \\
\text { causality by Naranjo } \\
\text { scale }^{36}(\mathrm{~N}=6 \mathrm{ADR})\end{array}$ & $\begin{array}{l}\text { Probable ADR } \\
\text { Possible }\end{array}$ & $\begin{array}{l}5 \\
1\end{array}$ & $\begin{array}{l}83.3 \\
16.7\end{array}$ \\
\hline
\end{tabular}

\section{Prevalence of DTPs Among the Study}

\section{Participants}

DTPs were identified in $76 \%$ of the study participants. A total of 449 DTPs were identified from 300 patients during the study period, in which, 1 DTP (minimum) and 5 DTPs (maximum) per patient were identified among patients with DTP. That equates with an average DTP of 449/228 (1.97), while 449/300 (1.5) among patients admitted to the surgery ward. The majority of DTPs are involved with the prescription of antimicrobials $(68.0 \%)$ (Table 3$)$.

\section{Types and Causes of DTPs by Indication of Use}

Dose too low 124/449 (27.6\%) and dose too high 81/449 (18.0\%) were found to be the most common types of DTPs among the study populations. Wrong low dose use (94/449) followed by inappropriate duration (longer duration of treatment or short frequency of administration) (65/449) were the most common causes of DTPs. Antimicrobials were the most common (73.8\%) contributing factor for DTPs followed by hematologic drugs (8.2\%) and cardiovascular drugs (6.0\%). The most common antimicrobial incurred in DTPs was "Ceftriaxone followed by Metronidazole". ${ }^{24}$ Additionally, Iron 21 (25\%), Tramadol \& Diclofenac 12 (14.3\%), Phenytoin 8 (9.5\%), and Statin $7(8.3 \%)$ were the most commonly identified non-antimicrobial drugs involved in DTPs (Table 3, Figures 2 and 3).

\section{The Role of Clinical Pharmacist in Identification and Resolution of DTPs}

After inappropriate utilization of drug therapy was identified, based on the feasibility and importance of intervention to the patients, appropriate interventional measures were taken by clinical pharmacists to correct the identified DTPs, with the intervention rate of $86.0 \%$ (196/228 per patients) and $86.2 \%$ (387/449 per DTPs). The acceptance rate from health-care providers and/or patients was $85.2 \%$ (167/196 patients) and $78 \%$ (302/387DTP). DTPs that were identified and intervened by the physician were not included in this study report. The most common type of intervention provided was, discontinue drug 116 (49.2\%) followed by add drug 36 (15.3\%), change dose, and change route 34 (14.4\%) for each. Among identified DTPs $302 / 449$ (67.3\%) was fully resolved by the clinical pharmacist, (Figure 1, Tables 3 and 4). 
Table 3 Types and Causes of DTPs

\begin{tabular}{|c|c|c|c|c|}
\hline Types of DTPs & Causes of DTPs & $\begin{array}{l}\text { Frequency of } \\
\text { DTP }\end{array}$ & Total & $\%$ \\
\hline $\begin{array}{l}\text { Drug therapy problem }(\mathrm{N}= \\
300)\end{array}$ & $\begin{array}{l}\text { Yes } \\
\text { No }\end{array}$ & & $\begin{array}{l}228 \\
72\end{array}$ & $\begin{array}{l}76.0 \\
24.0\end{array}$ \\
\hline Unnecessary drug therapy & $\begin{array}{l}\text { No medical condition } \\
\text { Overlapping effect } \\
\text { Non-pharmacologic (no need for SAP) preferred }\end{array}$ & $\begin{array}{l}27 \\
32 \\
7\end{array}$ & 66 & 14.7 \\
\hline Need additional drug therapy & $\begin{array}{l}\text { Prophylaxis needed and/or untreated indication } \\
\text { Additive or synergistic needed }\end{array}$ & $\begin{array}{l}37 \\
15\end{array}$ & 52 & 11.6 \\
\hline Need different drug & $\begin{array}{l}\text { More effective product available } \\
\text { Route not appropriate }\end{array}$ & $\begin{array}{l}19 \\
2\end{array}$ & 21 & 4.7 \\
\hline Dose too low & $\begin{array}{l}\text { The wrong dose ordered } \\
\text { Inappropriate frequency (longer) } \\
\text { Inappropriate duration (short) } \\
\text { The timing of SAP (too late or early) }\end{array}$ & $\begin{array}{l}94 \\
13 \\
2 \\
15\end{array}$ & 124 & 27.6 \\
\hline Potential or actual ADR & $\begin{array}{l}\text { Undesirable effect } \\
\text { Unsafe drug } \\
\text { DI lead to ADR } \\
\text { Contra-indication } \\
\text { Unsafe route }\end{array}$ & $\begin{array}{l}7 \\
12 \\
3 \\
3 \\
1\end{array}$ & 26 & 5.8 \\
\hline Dose too high & $\begin{array}{l}\text { The wrong dose ordered } \\
\text { Inappropriate duration (longer duration or short frequency) }\end{array}$ & $\begin{array}{l}16 \\
65\end{array}$ & 81 & 18.0 \\
\hline Non-compliance & $\begin{array}{l}\text { The patient did not understand important information/not } \\
\text { informed } \\
\text { Not willing to take } \\
\text { Cannot afford medication } \\
\text { Health professional forget to give }\end{array}$ & $\begin{array}{l}9 \\
1 \\
16 \\
4\end{array}$ & 30 & 6.7 \\
\hline Unclassified/other DTP & $\begin{array}{l}\text { Late to change IV to PO } \\
\text { Need monitoring }\end{array}$ & $\begin{array}{l}46 \\
2\end{array}$ & 48 & 10.7 \\
\hline \multicolumn{2}{|l|}{ Total DTPs } & 449 & 449 & 100 \\
\hline \multicolumn{2}{|c|}{ Mean of DTP per patient $(\mathrm{N}=228)$} & Min $=1$ & $\operatorname{Max}=5$ & 1.97 \\
\hline \multicolumn{2}{|c|}{ Intervention and acceptance status } & Frequency & \multicolumn{2}{|c|}{ Percentage } \\
\hline Intervention given & $\begin{array}{l}\text { Per patient }(\mathrm{N}=228) \\
\text { Per DTP }(\mathrm{N}=449)\end{array}$ & $\begin{array}{l}196 \\
387\end{array}$ & $\begin{array}{l}86 \\
86.2\end{array}$ & \\
\hline Acceptance of intervention & $\begin{array}{l}\text { Per patient }(N=196) \\
\text { Per DTP }(N=387)\end{array}$ & $\begin{array}{l}167 \\
302\end{array}$ & $\begin{array}{l}85.2 \\
78\end{array}$ & \\
\hline
\end{tabular}

Abbreviations: DTP, drug therapy problem; SAP, surgical antimicrobial prophylaxis; ADR, adverse drug reaction; DI, drug interaction; IV, intravenous; PO, per-oral, one problem can lead to more interventions and one level of acceptance per intervention proposed.

\section{Predictors of Drug Therapy Problem}

A stepwise forward multivariate logistic regression showed that only poly-pharmacy and length of hospital stay (LOS) in days were found to be the predictors for DTP among the independent variables. Age-adjusted Charlson CI, presence of co-morbidity, pre-admission medication, age, sex, income, ASA class, and CDC wound class were not significantly associated with DTPs. Accordingly, the patients with poly-pharmacy were about 7 times more likely to have DTP [AOR, 7.23; 95\% CI, 2.29-22.13: P-value $<0.001]$ relative to the patients with no poly-pharmacy. Similarly, compared with those who 


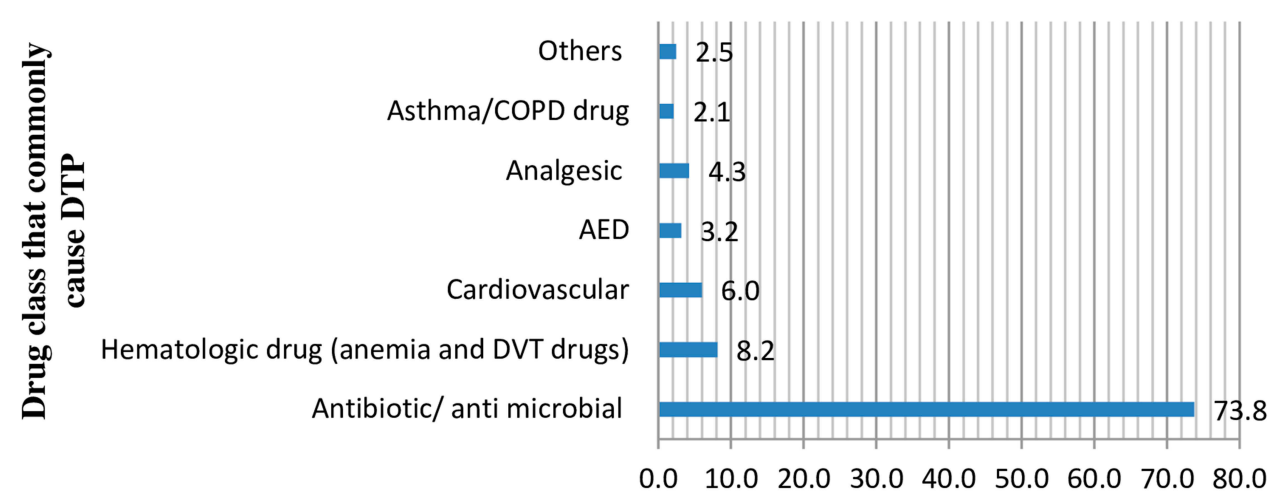

percentage of patients with $\operatorname{DTP}(\mathrm{N}=282 *)$

Figure 2 Drugs commonly involved in causing DTPs by pharmacologic and therapeutics class.

Notes: *There were multiple responses, others include diabetes mellitus, electrolyte, diuretic, gastrointestinal disorder.

Abbreviations: COPD, chronic obstructive pulmonary disease; AED, antiepileptic drug; DVT, deep venous thrombosis; DTP, drug therapy problem.

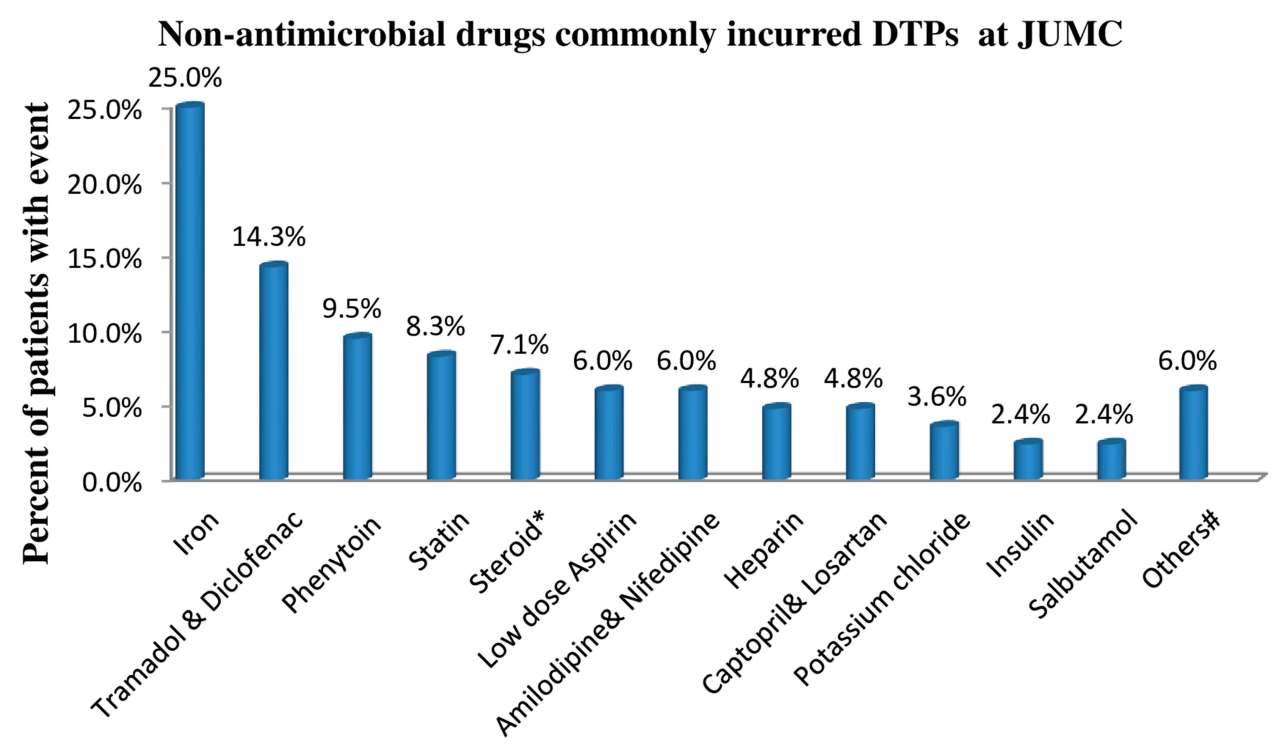

Specific Drugs

Figure 3 Specific non-antimicrobial drugs commonly incurred DTPs (total event= 84).

Notes: *Dexamethasone, hydrocortisone, and beclomethasone, "hydrochlorothiazide, theophylline, mannitol, metoclopramide, and pyridoxine.

stayed for $\leq 20$ days, the patients that stayed for $>20$ days were about 5 times more likely to have DTP [AOR, 5.42; 95\% CI, 2.74-10.70; $\mathrm{p}<0.001$ ] (Table 5).

\section{Discussion}

This was a 3 months hospital-based prospective observational and interventional study at the surgery ward of JUMC, intending to identify drug therapy problems (DTP) and role of clinical pharmacist in identification and resolution of DTPs with daily follow up (from admission date to discharge, through daily participation on medical round for providing intervention and to check whether an intervention was applied or not for the patient). Hence, a high rate of DTPs and acceptance rates for intervention was found among hospitalized patients.

There was no retrieved study that directly accessed DTP in the surgery ward; most of the study addressed the antimicrobial use issue. ${ }^{24,38}$ However, in addition to antimicrobials, patients in the surgical ward use different drug classes' for different disease conditions which needs a rational use for a better outcome. In general, irrespective of the ward, drug, or disease of concern, DTP was reported by different studies in different countries, with the prevalence of $33.3 \%$ to $99.4 \%{ }^{8,9,39-42}$ In similar ways, our study revealed a 
Table 4 The Role of Clinical Pharmacist in Resolving DTPs (Acceptance Rate), and Types of Interventions Provided to Health-Care Professionals and/or Patients

\begin{tabular}{|c|c|c|c|}
\hline $\begin{array}{l}\text { Common Type of Intervention Provided for the } \\
\text { Patients }^{\mathrm{a}}\end{array}$ & Antibiotic N (\%) & Non antibiotic $\mathbf{N}(\%)$ & $\begin{array}{l}\text { Total Intervention } \\
\mathbf{N}(\%)\end{array}$ \\
\hline $\mathrm{D} / \mathrm{C}$ drug(s) & $95(55.2)$ & $21(32.8)$ & $116(49.2)$ \\
\hline Add drug(s) & $10(5.8)$ & $26(40.6)$ & $36(15.3)$ \\
\hline Change dose (increase/decrease) & $27(15.7)$ & $7(10.9)$ & $34(14.4)$ \\
\hline Change route (IV to PO) & $31(18.0)$ & $3(4.7)$ & $34(14.4)$ \\
\hline Change drug product/dosage form & $8(4.7)$ & $4(6.3)$ & $12(5.1)$ \\
\hline Compliance/counseling & $\mathrm{I}(0.6)$ & $3(4.7)$ & $4(1.7)$ \\
\hline Total number of patients intervention given (multiple response) & $172(100)$ & $64(100)$ & $236(100)$ \\
\hline \multicolumn{3}{|l|}{ Number of Intervention and Status of Intervention } & Total N (\%) \\
\hline \multirow[t]{2}{*}{ The planned interventions ( $N=449 \mathrm{DTPs} / 228$ patients) } & No intervention & $62 \mathrm{DTPs} / 32$ patients & $32 / 228(14.0)$ \\
\hline & $\begin{array}{l}\text { Intervention at } \\
\text { patient/prescriber/ } \\
\text { drug level }\end{array}$ & 387 DTPs/I 96 patients & $196 / 228(86.0)$ \\
\hline \multirow{3}{*}{$\begin{array}{l}\text { Acceptance of the intervention per patient }(\mathrm{N}=236) \text {, ie }(172 \\
\text { patients related to antibiotic }+64 \text { patients related to } \\
\text { nonantibiotic) }\end{array}$} & $\begin{array}{l}\text { Intervention accepted } \\
\text { and fully implemented }\end{array}$ & $\begin{array}{l}\text { II patients (antibiotic) } \\
+48 \text { patients (non antibiotic) }\end{array}$ & $165 / 236$ (69.9\%) \\
\hline & $\begin{array}{l}\text { Intervention accepted } \\
\text { and partially } \\
\text { implemented }\end{array}$ & $\begin{array}{l}\text { I6 patients (antibiotic) }+11 \\
\text { patients (non antibiotic) }\end{array}$ & $27 / 236$ (II.4\%) \\
\hline & $\begin{array}{l}\text { Intervention not } \\
\text { accepted }\end{array}$ & $\begin{array}{l}39 \text { patients (antibiotic) }+5 \\
\text { patients (non antibiotic) }\end{array}$ & $44 / 236(18.6 \%)$ \\
\hline \multirow{2}{*}{$\begin{array}{l}\text { Status of the DTP solving (outcome) per problem }(\mathrm{N}=449 \\
\text { DTPs) }\end{array}$} & Problem totally solved & 302 DTPs & $302 / 449$ (67.3\%) \\
\hline & Not solved & $\begin{array}{l}62 \text { DTPs (no intervention) }+85 \\
\text { DTPs (intervention not } \\
\text { accepted) }\end{array}$ & $147 / 449$ (32.7\%) \\
\hline
\end{tabular}

Notes: ${ }^{\mathrm{a}}$ For the type of interventions provided, only one intervention per person was listed as an example (ie, it could be greater than this because per individual there were one or more interventions).

Abbreviations: D/C, discontinue; IV, intravenous; PO, per oral; DTP, drug therapy problem.

prevalence of DTP $(76 \%)$ with that of retrieved data, during their hospital stay. Our study identified an average of 1.5 DTPs per patient; this is roughly inline with other studies. For instance, in medical wards: on average 1.7 to 2.6 DTPs per patient, ${ }^{12,39,43}$ and in surgery wards: in average 0.72 to 1.3 DTPs per patient ${ }^{8,40}$ was reported. Therefore, this is an indication that patients in the surgery ward warrant pharmaceutical care like patients in other wards rather than thinking surgical patients as less prone to DTP. ${ }^{15}$ Ethiopia is striving to fill gaps in surgical care by $2030 .^{44}$ Thus, the view of the stakeholder has to be changed from "the idea of a high prevalence of DTP only in the internal medicine ward and vulnerability of the patient population in the pediatric ward"15 to "the idea of all patients needs pharmaceutical care".

Antimicrobials (73.8\%) followed by hematologic drugs $(8.2 \%)$ and cardiovascular drugs $(6.0 \%)$, were the most commonly implicated drugs in DTPs. Similar to this finding, antibiotics ${ }^{45}$ were the most implicated drugs in DTP. In contrary to our study finding, other studies depicted beta-blockers followed by angiotensin-converting enzyme inhibitors, ${ }^{43}$ Tramadol followed by antidepressants ${ }^{12}$ were the most common drugs encountered in DTPs. This variation could be explained in part by the difference between wards; surgery ward versus medical ward or disease, for instance, patient with heart failure only. ${ }^{43}$

This study disclosed $31 \%$ of drug-drug interaction among the study participants, which was similar to other studies report (21\% to $49.7 \%) .{ }^{12,46}$ The current study reported that actual ADR was $1.67 \%$ while most of the ADRs were probable in $83.3 \%$ according to Naranjo scale, ${ }^{36}$ this was comparable to retrieved study result $1.46 \%$ actual and probable ADRs (51.0\%). ${ }^{45}$

Regarding the type of DTPs, our study showed that dose too low followed by dose too high were found to be 
Table 5 Result of Multiple Stepwise Forward Logistic Regressions to Predict the Factors Related to DTP Occurrences

\begin{tabular}{|c|c|c|c|c|c|c|}
\hline \multirow[t]{2}{*}{ Variables } & \multirow[t]{2}{*}{ Category } & \multicolumn{2}{|l|}{ DTP } & \multirow[t]{2}{*}{ AOR } & \multirow[t]{2}{*}{$95 \% \mathrm{Cl}$} & \multirow[t]{2}{*}{$P$ value } \\
\hline & & No (\%) & Yes (\%) & & & \\
\hline Poly-pharmacy & $\begin{array}{l}\text { No } \\
\text { Yes }\end{array}$ & $\begin{array}{l}58(35.6) \\
14(10.2)\end{array}$ & $\begin{array}{l}105(64.4) \\
123(89.8)\end{array}$ & $\begin{array}{l}1 \\
7.269\end{array}$ & $2.388-22.131$ & 0.000 \\
\hline Length of hospital stay & $\begin{array}{l}\leq 20 \text { days } \\
>20 \text { days }\end{array}$ & $\begin{array}{l}68(28.9) \\
4(6.2)\end{array}$ & $\begin{array}{l}167(71.1) \\
61(93.8)\end{array}$ & $\begin{array}{l}1 \\
5.418\end{array}$ & $2.743-10.700$ & 0.000 \\
\hline
\end{tabular}

Abbreviations: AOR, adjusted odds ratio; DTP, drug therapy problem.

the most common types of DTPs among the study populations. Even though there was an inconsistent way of classifying and reporting DTPs, it was reported by different studies that the most common type of DTPs was dosage too low followed by ineffective drug therapy; ${ }^{43}$ an untreated indication or need additional drug therapy followed by high medication dosage. ${ }^{39}$ Another study added that the most common type of DTPs was unnecessary drug therapy followed by needs additional drug therapy. ${ }^{14}$

The role of clinical pharmacists in the identification and resolution of DTPs was accessed and documented with a different result in general medical wards ${ }^{12,20,42,47-50}$ and the Surgery ward ${ }^{8,21}$ with more intention of antimicrobial userelated problems, throughout the world. But, there was no data in Ethiopian Surgical wards and few data in medical wards that accessed the role of clinical pharmacists in identification and resolution of DTPs. ${ }^{14}$

The current study identified 449 DTPs/300 patients, with the intervention rate of $86.0 \%$ per patient, and $86.2 \%$ per problem. The acceptance rate from health-care providers and/or patients were $85.2 \%$ per patient and $78 \%$ per problem. This result is in line with other studies in supporting the role of clinical pharmacists in the identification and resolution of DTPs. For instance, a clinical pharmacists's intervention was in the range of $49 \%$ to 89.3\% per problem. ${ }^{12,14}$ Apart from; the acceptance rate was reported in the range of $47 \%$ to $93 \%$, with a higher acceptance rate in developing countries. ${ }^{12,14,20,42,51-54}$

The current study depicted that the most common type of interventions provided were: discontinue $\operatorname{drug}(\mathrm{s})$ followed by add drug(s), change dose, and change route which was roughly similar with other studies. For instance, the most common interventions provided by Clinical Pharmacists were: add a drug, rectification of incomplete prescriptions, change of drug or dosage, and discontinue drug by the first study; ${ }^{52}$ while add drug followed by reduce dose by the second study $;{ }^{53}$ and reduce dose by the third study.$^{42}$
It is known that different obstacles exist for low- and middle-income countries to provide quality surgical care. ${ }^{54}$ Even though Ethiopia is striving to meet the gaps in surgical care, across all levels of the health-care system by $2030,{ }^{44}$ the high prevalence of DTP in the surgical ward, lack of support from the hospital management to strengthen the clinical pharmacy service, and the lack of assigned clinical pharmacist to this ward make the goal partly unachievable. ${ }^{15}$ Indeed, the result of the current study is one indicator for the possibility of improving the quality of health care for patients' in the surgery ward, through the incorporation of clinical pharmacists, provided that their interventions were accepted and implemented.

On the other hand, knowing the predictors for the occurrence of DTPs is paramount in increasing patient safety, while, reducing harm to patients. Similar to other studies report, poly-pharmacy $(\mathrm{P}<0.001),{ }^{39,40,43,55}$ and length of hospital stay $>20$ days $(\mathrm{p}<0.001)^{56}$ were independent predictors for DTPs occurrence. As the number of drugs increases, there is an increment in drug interaction or unnecessary overlap, un-affordability, etc., which in turn results in a proportional increase in DTPs. Furthermore, the longer the hospital stay, the more the total number of drug exposure and/or the more hospitalacquired infection which needs treatment, hence, the more probable of DTPs occurrence.

As a limitation of this study, it did not assess the severity of those DTPs. Despite the prevalence of DTP which could be generalizable to most of the Ethiopian referral Hospitals, where the clinical pharmacy service in the surgery ward is neglected; ${ }^{15}$ however, its generalizability in-terms of intervention provided and acceptance rate was in question. ${ }^{15}$ The first reason is being a single center and the second is the quality of service provided by master clinical pharmacist is different from that of the first degree (where most of the service is provided by the first degree); in terms of confidence, communication \& clinical 
skill, knowledge, and reliability of his/her recommendation by physicians. ${ }^{15}$

\section{Conclusion and Recommendation}

It was concluded that there was a high prevalence of drug therapy problems in the study area; majorly contributed by antimicrobial use followed by hematologic drugs. The most common type of DTP was dose too low, dose too high, unnecessary drug therapy, and need additional drug therapy, respectively. Only poly-pharmacy and length of hospital stay (LOS) in days were found to be the independent predictors for DTP.

There was a high level of DTPs identification and resolution as it was indicated by the high number of DTPs identified, high rate of intervention provided as well as the high rate of DTPs fully resolved by clinical pharmacists during the study period in the Surgery ward. The most common interventions provided were discontinuing a drug; add a drug, followed by change dose, and change the route, respectively. The government should continue to include and strengthen clinical pharmacist service in each hospital, including the surgery ward to reduce these problems and increase the patient's drug therapy outcome, to save lives through safe surgery by $2030,{ }^{44}$ because, if those problems are left undetected and unresolved it could lead to harm.

\section{Data Sharing Statement}

The datasets during and/or analyzed during the current study available from the corresponding author on reasonable request.

\section{Ethics and Consent Statement}

The ethical clearance was obtained from Jimma University, Institute of Health; Institutional Review Board under protocol number IHRPGQ/103/207. Written informed consent was obtained from participants.

\section{Acknowledgments}

We would like to thank Jimma University for funding. Besides, with our deepest gratitude, we want to acknowledge Dr. Fikadu Negash (Assistant professor of surgery) and the study participants.

\section{Author Contributions}

All authors made substantial contributions to conception and design, acquisition of data, or analysis and interpretation of data; took part in drafting the article or revising it critically for important intellectual content; gave final approval of the version to be published; and agree to be accountable for all aspects of the work.

\section{Funding}

The source of funding was Jimma University as postgraduate research.

\section{Disclosure}

The authors declare that they have no competing interests.

\section{References}

1. GRdS D, Rotta ET, Goldim JR. Medication errors: classification of seriousness, type, and of medications involved in the reports from a University Teaching Hospital. Braz J Pharm Sci. 2013;49(4):793802. doi:10.1590/S1984-82502013000400019

2. Lovely JK, Hyland SJ, Smith AN, Nelson G, Ljungqvist O, Parrish II RH. Clinical pharmacist perspectives for optimizing pharmacotherapy within Enhanced Recovery After Surgery $\left(\right.$ ERAS $\left.^{\circledR}\right)$ Programs. Int J Surg. 2019;63:58-62. doi:10.1016/j.ijsu.2019.01.006

3. FF MT, MA S. Prevalence and risk factors associated with post operative infections in the Limbe Regional Hospital of Cameroon. Open Surg J. 2014;8(1):1-8. doi:10.2174/1874300501408010001

4. Kennedy J, Van Rij A, Spears G, Pettigrew R, Tucker I. Polypharmacy in a general surgical unit and consequences of drug withdrawal. Br J Clin Pharmacol. 2000;49(4):353-362. doi:10.1046/ j.1365-2125.2000.00145.x

5. Hepler CD. Clinical pharmacy, pharmaceutical care, and the quality of drug therapy. Pharmacotherapy. 2004;24(11):1491-1498. doi:10. 1592/phco.24.16.1491.50950

6. Pharmaceutical Care Network Europe Classification for Drug Related Problems PCNE Working group on drug-related problems; 2017. Available from: https://www.pcne.org/upload/files/152_PCNE_classi fication_V7-0.pdf. Accessed February, 2019.

7. Lee JK, Alshehri S, Kutbi HI, Martin JR. Optimizing pharmacotherapy in elderly patients: the role of pharmacists. Integr Pharm Res Pract. 2015;4:101. doi:10.2147/IPRP.S70404

8. Ngige G, Carton E, Zaborowski A, Brown A, Conyard E, Gaskin J. 4CPS-239 Evaluation of Clinical Pharmacist Interventions in Surgical Patients. British Medical Journal Publishing Group; 2018.

9. Nanji KC, Patel A, Shaikh S, Seger DL, Bates DW. Evaluation of perioperative medication errors and adverse drug events. Anesthesiology. 2016;124(1):25-34. doi:10.1097/ALN.0000000000000904

10. Ernst FR, Grizzle AJ. Drug-related morbidity and mortality: updating the cost-of-illness model. J Am Pharm Assoc (1996). 2001;41 (2):192-199. doi:10.1016/S1086-5802(16)31229-3

11. Silva C, Ramalho C, Luz I, Monteiro J, Fresco P. Drug-related problems in institutionalized, polymedicated elderly patients: opportunities for pharmacist intervention. Int J Clin Pharm. 2015;37 (2):327-334. doi:10.1007/s11096-014-0063-2

12. Guignard B, Bonnabry P, Perrier A, Dayer P, Desmeules J, Samer CF. Drug-related problems identification in general internal medicine: the impact and role of the clinical pharmacist and pharmacologist. Eur $J$ Intern Med. 2015;26(6):399-406. doi:10.1016/j.ejim.2015.05.012

13. Pedersen CA, Schneider PJ, Scheckelhoff DJ. ASHP national survey of pharmacy practice in hospital settings: prescribing and transcribing -2016. Am J Health Syst Pharm. 2017;74(17):1336-1352. doi:10. 2146/ajhp170228

14. Mekonnen AB, Yesuf EA, Odegard PS, Wega SS. Implementing ward based clinical pharmacy services in an Ethiopian University Hospital. Pharm Pract. 2013;11(1):51. doi:10.4321/S1886-365520 13000100009 
15. Bilal AI, Tilahun Z, Gebretekle GB, Ayalneh B, Hailemeskel B, Engidawork E. Current status, challenges and the way forward for clinical pharmacy service in Ethiopian public hospitals. BMC Health Serv Res. 2017;17(1):359. doi:10.1186/s12913-017-2305-1

16. De Bock L, Tommelein E, Baekelandt H, Maes W, Boussery K, Somers A. The introduction of a full medication review process in a local hospital: successes and barriers of a pilot project in the geriatric ward. Pharmacy. 2018;6(1):21. doi:10.3390/pharmacy6010021

17. Sjölander M, Gustafsson M, Gallego G. Doctors' and nurses' perceptions of a ward-based pharmacist in rural northern Sweden. Int J Clin Pharm. 2017;39(4):953-959. doi:10.1007/s11096-017-0488-5

18. Tegegn HG, Abdela OA, Mekuria AB, Bhagavathula AS, Ayele AA. Challenges and opportunities of clinical pharmacy services in Ethiopia: a qualitative study from healthcare practitioners' perspective. Pharm Pract. 2018;16(1).

19. Tsega B, Bhagavathula AS, Sarkar BR, Melaku T, Shewamene Z. impact of clerkship attachments on students' attitude toward pharmaceutical care in Ethiopia. Adv Med Educ Pract. 2015;6:385. doi:10. 2147/AMEP.S80802

20. Lee Y, Gettman L. Descriptive analysis of acceptance by prescribers and economic benefit of pharmacist recommended interventions in a critical care unit. Inov Pharm. 2018;9(2):15. doi:10.24926/iip.v9i2.958

21. Luo H, Fan Q, Xiao S, Chen K. Impact of clinical pharmacist interventions on inappropriate prophylactic acid suppressant use in hepatobiliary surgical patients undergoing elective operations. PLoS One. 2017;12(10):e186302. doi:10.1371/journal.pone.0186 302

22. Polgreen LA, Han J, Carter BL, et al. Cost-effectiveness of a physician-pharmacist collaboration intervention to improve blood pressure control. Hypertension. 2015;66(6):1145-1151. doi:10.11 61/HYPERTENSIONAHA.115.06023

23. Kucukarslan SN, Peters M, Mlynarek M, Nafziger DA. Pharmacists on rounding teams reduce preventable adverse drug events in hospital general medicine units. Arch Intern Med. 2003;163(17):2014-2018. doi:10.1001/archinte.163.17.2014

24. Tefera GM, Feyisa BB, Kebede TM. Antimicrobial use-related problems and their costs in surgery ward of Jimma University Medical Center: prospective observational study. PLoS One. 2019;14(5):1-15. doi:10.1371/journal.pone. 0216770

25. Cipolle R, Strand L, Morley P, Kellenberger T, Frakes M. Pharmaceutical Care of Patients and Documentation System Therefor. Google Patents; 2006.

26. Bratzler DW, Dellinger EP, Olsen KM, et al. Clinical practice guidelines for antimicrobial prophylaxis in surgery. Surg Infect. 2013;14 (1):73-156. doi:10.1089/sur.2013.9999

27. Allegranzi B, Bischoff $\mathrm{P}$, de Jonge $\mathrm{S}$, et al. New WHO recommendations on preoperative measures for surgical site infection prevention: an evidence-based global perspective. Lancet Infect Dis. 2016;16 (12):. doi:10.1016/S1473-3099(16)30197-9

28. January CT, Wann LS, Alpert JS, et al. 2014 AHA/ACC/HRS guideline for the management of patients with atrial fibrillation: executive summary: a report of the American College of Cardiology/American Heart Association Task Force on practice guidelines and the Heart Rhythm Society. J Am Coll Cardiol. 2014;64(21):2246-2280. doi:10.1016/j.jacc.2014.03.021

29. Ibanez B, James S, Agewall S, et al. 2017 ESC Guidelines for the management of acute myocardial infarction in patients presenting with ST-segment elevation: the Task Force for the management of acute myocardial infarction in patients presenting with ST-segment elevation of the European Society of Cardiology (ESC). Eur Heart J. 2017;39(2):119-177.

30. Yancy CW, Jessup M, Bozkurt B, et al. 2017 ACC/AHA/HFSA Focused Update of the 2013 ACCF/AHA Guideline for the Management of Heart Failure: A Report of the American College of Cardiology/American Heart Association Task Force on Clinical Practice Guidelines and the Heart Failure Society of America. $J$ Am Coll Cardiol. 2017;70(6):776-803. doi:10.1016/j.jacc.2017.04.025
31. Carey RM, Whelton PK. Prevention, detection, evaluation, and management of high blood pressure in adults: synopsis of the 2017 American College of Cardiology/American Heart Association hypertension guideline. Ann Intern Med. 2018;168(5):351-358. doi:10.73 26/M17-3203

32. Association AD. Standards of medical care in diabetes-2016: summary of revisions. Diabetes Care. 2016;39(1):S4-S5. doi:10.2337/ dc16-S003

33. DiPiro JT, Talbert RL, Yee GC, Matzke GR, Wells BG, Posey LM. Pharmacotherapy: A Pathophysiologic Approach Vol. 6. McGrawHill Education New York; 2014.

34. Alldredge BK, Corelli RL, Ernst ME, et al. Koda-Kimble and Young's Applied Therapeutics: The Clinical Use of Drugs. Wolters Kluwer Health Adis (ESP); 2013.

35. Chang C-M, Yin W-Y, Wei C-K, et al. Adjusted age-adjusted Charlson comorbidity index score as a risk measure of perioperative mortality before cancer surgery. PLoS One. 2016;11(2):e0148076. doi:10.1371/journal.pone.0148076

36. Naranjo CA, Busto U, Sellers EM, et al. A method for estimating the probability of adverse drug reactions. Clin Pharmacol Ther. 1981;30 (2):239-245. doi:10.1038/clpt.1981.154

37. AbuRuz SM, Bulatova NR, Yousef AM, Al-Ghazawi MA, Alawwa IA, Al-Saleh A. Comprehensive assessment of treatment related problems in hospitalized medicine patients in Jordan. Int $J$ Clin Pharm. 2011;33:501-511. doi:10.1007/s11096-011-9497-y

38. Abula T, Kedir M. The pattern of antibiotic usage in surgical inpatients of a teaching hospital, northwest Ethiopia. Ethiop J Health Dev. 2004;18(1):35-38. doi:10.4314/ejhd.v18i1.9863

39. Tigabu BM, Daba D, Habte B. Drug-related problems among medical ward patients in Jimma university specialized hospital, Southwest Ethiopia. J Res Pharm Pract. 2014;3(1):1. doi:10.4103/2279-042X. 132702

40. Gyimesi N, Soós G, Matuz M, et al. PS-104 Initiative for Improving Medicines Safety in Surgical Inpatients. British Medical Journal Publishing Group; 2015.

41. Vessal G, Namazi S, Davarpanah M, Foroughinia F. Evaluation of prophylactic antibiotic administration at the surgical ward of a major referral hospital, Islamic Republic of Iran. East Mediterr Health J. 2011;17:663-668. doi:10.26719/2011.17.8.663

42. Perlman A, Horwitz E, Hirsh-Raccah B, et al. Clinical pharmacist led hospital-wide direct oral anticoagulant stewardship program. Isr J Health Policy Res. 2019;8(1):19. doi:10.1186/s13584-019-0285-9

43. Niriayo YL, Kumela K, Kassa TD, Angamo MT. Drug therapy problems and contributing factors in the management of heart failure patients in Jimma University Specialized Hospital, Southwest Ethiopia. PLoS One. 2018;13(10):e0206120. doi:10.1371/journal. pone. 0206120

44. Burssa D, Teshome A, Iverson K, et al. Safe surgery for all: early lessons from implementing a national government-driven surgical plan in Ethiopia. World J Surg. 2017;41(12):3038-3045. doi:10. 1007/s00268-017-4271-5

45. Sundaran S, Udayan A, Hareendranath K, et al. Study on the classification, causality, preventability and severity of adverse drug reaction using spontaneous reporting system in hospitalized patients. Pharmacy. 2018;6(4):108. doi:10.3390/pharmacy6040108

46. Cruciol-Souza JM, Thomson JC. Prevalence of potential drug-drug interactions and its associated factors in a Brazilian teaching hospital. J Pharm Pharm Sci. 2006;9(3):427-433.

47. Ravn-Nielsen LV, Duckert M-L, Lund ML, et al. Effect of an inhospital multifaceted clinical pharmacist intervention on the risk of readmission: a randomized clinical trial. JAMA Intern Med. 2018;178 (3):375-382. doi:10.1001/jamainternmed.2017.8274

48. Ali MAS, Khedr EMH, Ahmed FAH, Mohamed NNE. Clinical pharmacist interventions in managing drug-related problems in hospitalized patients with neurological diseases. Int J Clin Pharm. 2018;40(5):1257-1264. doi:10.1007/s11096-018-0658-0 
49. Bayoud T, Waheedi M, Lemay J, Awad A, editors. Drug therapy problems identification by clinical pharmacists in a private hospital in Kuwait. In: Annales pharmaceutiques francaises; Vol. 76. Elsevier; 2018:210-217.

50. Heselmans A, van Krieken J, Cootjans S, et al. Medication review by a clinical pharmacist at the transfer point from ICU to ward: a randomized controlled trial. J Clin Pharm Ther. 2015;40(5):578583. doi: $10.1111 /$ jcpt. 12314

51. Ojeh VB, Naima N, Abah IO, et al. Pattern of drug therapy problems and interventions in ambulatory patients receiving antiretroviral therapy in Nigeria. Pharm Pract. 2015;13(2):1-6. doi:10.18549/PharmPract.20 15.02 .566

52. Allenet B, Bedouch P, Brudieu E, et al. Physicians' acceptance of pharmacy residents' recommendations on drug therapy. Pharm Educ. 2018;4(2).
53. Pepe GM, Kaefer TN. Impact of pharmacist identification of medication-related problems in a nontraditional long-term care pharmacy. $J$ Am Pharm Assoc. 2018;58(4):S51-S54. doi:10.1016/j.japh.2018.04. 026

54. Huynh C, Huynh MN. The Global Burden of Surgical Disease: An Analysis of Inaccessible Surgical Care in Low and Middle Income Countries. RiSS.IjHS. 2018;7(1):1-15. doi:10.18192/riss-ijhs. v7i1.2135

55. Ogbonna B, Ezenduka C, Opara C, Ahara L. Drug therapy problems in patients with Type-2 Diabetes in a tertiary hospital in Nigeria. Int $J$ Innov Res Dev. 2014;3(1):494-502.

56. Yadesa TM, Gudina EK, Angamo MT. Antimicrobial use-related problems and predictors among hospitalized medical in-patients in Southwest Ethiopia: prospective observational study. PLoS One. 2015;10(12):e0138385. doi:10.1371/journal.pone.0138385

\section{Publish your work in this journal}

Drug, Healthcare and Patient Safety is an international, peer-reviewed open-access journal exploring patient safety issues in the healthcare continuum from diagnostic and screening interventions through to treatment, drug therapy and surgery. The journal is characterized by the rapid reporting of reviews, original research, clinical, epidemiological and post-marketing surveillance studies, risk management, health literacy and educational programs across all areas of healthcare delivery. The manuscript management system is completely online and includes a very quick and fair peer-review system. Visit $\mathrm{http}: / /$ www.dovepress.com/testimonials.php to read real quotes from published authors. 